\title{
The happiness of foundation doctors training in the North West Deanery
}

\author{
Author: Bethany Ferris
}

\begin{abstract}
Aims
A survey was created to explore how happy foundation doctors are during training.

\section{Methods}

The survey was created online using SurveyMonkey and piloted in the Isle of Man. The survey contained 38 questions and explored doctors' feelings over the past 2 months of work. The online link was distributed to all foundation programme administrators of trusts within the North West Deanery. 21 trusts confirmed that the link had been sent to their foundation trainees. The link was open from 20 November 2017 to 7 January 2018.
\end{abstract}

\section{Results}

One-hundred and eighty responses were collected from an even number of men, women and grades of foundation doctor. $60 \%$ of foundation doctors enjoyed being at work. For data analysis, the questions were grouped into eight categories: education, staffing, wellbeing and support, recognition of worth, rota, working conditions, information technology and miscellaneous. Respondents were not satisfied with their education: only $39 \%$ 'strongly agree' or 'agree' that they receive regular constructive feedback and, when asked how often their weekly foundation teaching was relevant and high quality, the mean response was $49 \%$ of the time. Many respondents wanted 'better formal teaching, ours is poor and a completely wasted opportunity' and 'more feedback on day-to-day work'. Staffing was another category about which respondents were unhappy: $58 \%$ 'strongly agree' or 'agree' that the lack of continuity of staff has negatively affected their team and $7 \%$ of people said that they are always too busy to provide adequate patient care. Perhaps more concerning is that $41 \%$ of people feel that they are too busy to provide adequate patient care for over $50 \%$ of the time they are at work. Despite this, $64 \%$ of respondents stated that they were well supported at work and $66 \%$ have a supportive clinical and educational supervisor. $76 \%$ felt motivated at work. The majority of doctors did not feel recognised for their worth: only $37 \%$ of respondents felt thst they get paid appropriately and many wanted 'better pay reflective of other trained professionals such as lawyers' and 'to be thanked and recognised by the trust'. With regards to the rota, only $41 \%$ of people said that they received their rota well in advance of starting their job. Only $43 \%$ of people felt they had a good work-life balance. Many comments were made on working conditions, with doctors wanting better staff areas and availability of fairly priced food and drink. When asked about future career plans, $41 \%$ of people felt that their trust had helped them to progress their career and, similarly, $40 \%$ of doctors planned to enter further training straight after completion of their foundation training. We received 474 individual written comments on what would make doctors happier at work. $23 \%$ of the comments were regarding better education and $19 \%$ concerned better staffing.

\section{Conclusions}

Overall, $60 \%$ of foundation doctors enjoy working. The results of this survey have revealed some key areas for improvement of foundation training programmes, such as education and feedback, staffing levels, availability of rotas prior to placements and help with career planning. Our results differ from those reported in the 2017 General Medical Council national training survey; this survey looked specifically at foundation doctors. An extensive range of factors that influence happiness were assessed and doctors were given the opportunity to write comments. The survey was written by a foundation doctor and therefore, I believe it provides highly relevant and honest feedback. These results can be used to enhance foundation training programmes.

\section{Conflict of interest statement}

The author declares no conflict of interest. 